\title{
A THREE DIMENSIONAL MESHFREE-SIMULATION OF THE SELECTIVE LASER SINTERING PROCESS WITH CONSTANT THERMAL COEFFICIENTS APPLIED TO NYLON 12 POWDERS
}

\author{
H. YAAGOUBI ${ }^{1 *}$, H. ABOUCHADI ${ }^{1}$ \\ 1. Laboratory of Applied Mechanics and Technologies (LAMAT), ENSET, STIS Research Center Mohammed V \\ University, RABAT- Morocco, *email: yaagoubi.hanan@gmail.com.
}

\begin{abstract}
$3 \mathrm{D}$ printing is an intersting process in the context of creating original objects.Selective laser sintering printers use a laser to fuse polyamide particles together with specific resin and heat. The difference in temperature between the different areas in the process causes the appearance of deformations, the objective of this work is the modeling of the thermal SLS phenomenona, by following the evolution of the temperature as a function of time.This model is based on the resolution of the heat conduction equation coupling with convection and radiation conditions with a distribution heat source and constant thermal coefficients by the meshless method based on radial basis function, the result of this study,will be presented and compared with other works.
\end{abstract}

Keywords : Meshfree method; radical basis function (RBF) ; thermal modeling; heat transfer ; selective laser sintering(SLS).

\section{Introduction}

Recently, the use of 3D printing has moved from the development stage in research laboratoris to the implementation stage on industrial production sites. Selective laser sintering enables manufacturing precise and durable plastic parts with low deformations, due to the better mechanical properties associated with the appearance quality. Numerical modeling is a suited tool for predicting certain characteristics of the final parts, and for the optimization of the laser process. Many numerical and analytical studies have been made to solve the transient problems of heat transfer of iridium objects by a source term [1-3].In this study, a meshless methods is applied using radial basis functions (RBFs) which results prove it's effecient in solving radiative and conductive heat transfer coupled in the absorbing, emitting and diffusing media [4]. The MQ RBF approach created by kansah since 1990 has a successful history of numerical applications and its particularly attractive which is simple, accurate, and requires polygonalisation $[5,6]$.

\section{The SLS thermal process modelization}

The main aim of the present work is to follow the evolution of temperature over time in the process of SLS, the transient conduction equations are written under the following assumptions :

- A complete model describes the thermal history shown in Fig. 1 within the powder bed, taking into account a heat distrubition and the convection in the SLS build chamber as a natural convection with radiation at the boundary.

- The polyamide powder bed was assumed to be homogeneous and continuous.

- The heat flux from the laser beam was modelled as Gaussian-distributed heat flux and was given directly on the top of the polyamide powder bed.

- Considering the constant coefficients thermal proprieties ( no changing with temperature).

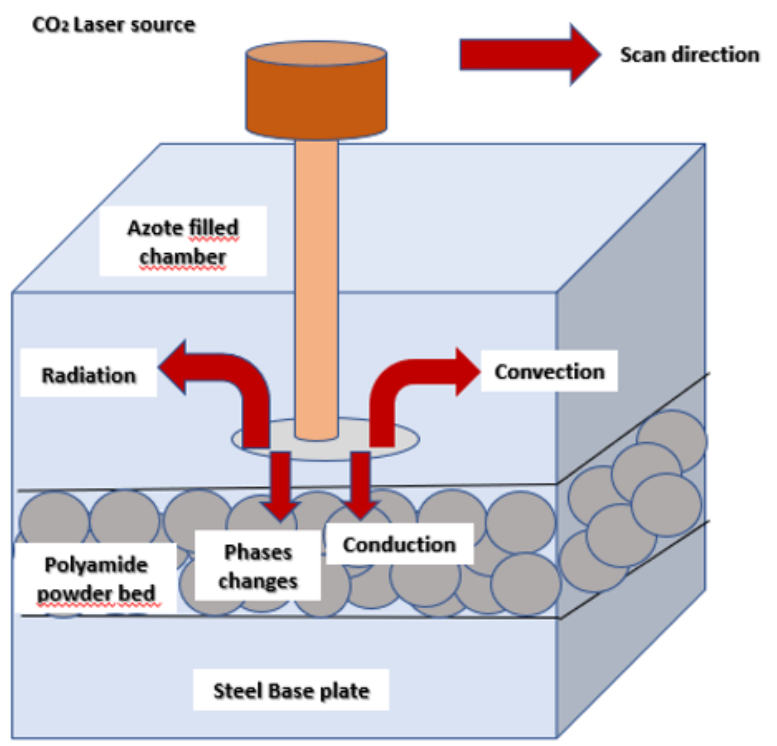

Fig.1 : Descriptive diagram of the SLS process

\subsection{Linear Heat Transfer Equation In Meshless RBF}

Thermal transfers are described by the following heat transfert equation as in [1,2] and [7-13]: 


$$
\frac{\partial T}{\partial t}=\frac{K_{e}}{C_{p} \rho}\left(\frac{\partial T^{2}}{\partial x^{2}}+\frac{\partial T^{2}}{\partial y^{2}}+\frac{\partial T^{2}}{\partial z^{2}}\right)+Q_{v}
$$

The powder bed is initially at ambient temperature and we have imposed conditions of convective flux and radiation at the limits of the domain.

- Initial condition :

For $\mathrm{t}=0 \mathrm{~s}, \mathrm{~T}(\mathrm{x}, \mathrm{y}, \mathrm{z}, 0)=130 \mathrm{C}^{\circ}$ (Preheating temperature)

\section{- Boundary conditions :}

For the simplification of the modeling, the radiation term was integrated into convection term, it's can be expressed in $\mathrm{Z}$ direction, as follows [2]:

For $\mathrm{Z}=0,-\mathrm{K}_{\mathrm{e}} \frac{\partial \mathrm{T}}{\partial \mathrm{Z}}=\mathrm{h}(\mathrm{Tz}-\mathrm{Te})$

No heat loss at the bottom:

$$
-\mathrm{K}_{\mathrm{e}} \frac{\partial \mathrm{T}}{\partial \mathrm{Z}} \text { bottom }=0
$$

The polyamide powder used in present study is nylon 12 , having the following physical properties listed in Table 1, which their values are taken from [1] :

Table 1: Thermo-physical properties of nylon12

\begin{tabular}{c|c|c|c}
\hline $\begin{array}{c}\text { Thermal } \\
\text { properties }\end{array}$ & Full name & Value & Unit \\
\hline $\mathbf{K e}$ & $\begin{array}{c}\text { Thermal } \\
\text { conductivity }\end{array}$ & 0.28 & $\mathrm{w} / \mathrm{mk}$ \\
\hline To & $\begin{array}{c}\text { Initial bed } \\
\text { temperature }\end{array}$ & 130 & $\mathrm{C}^{\circ}$ \\
\hline $\mathbf{C p}$ & Specific heat & 1090 & $(\mathrm{~J} / \mathrm{kg} / \mathrm{K})$ \\
\hline $\boldsymbol{\rho}$ & Initial density & 1030 & $\mathrm{~kg} / \mathrm{m}^{3}$ \\
\hline $\boldsymbol{Q}_{\boldsymbol{V}}$ & Heat source & - & $\left(\mathrm{w} / \mathrm{m}^{2}\right)$ \\
\hline $\mathbf{h}$ & $\begin{array}{c}\text { Convection } \\
\text { coefficient }\end{array}$ & 25 & $\mathrm{j} / \mathrm{sm}^{2} \mathrm{k}$ \\
\hline $\mathbf{T e}$ & $\begin{array}{c}\text { Temperature } \\
\text { of the chamber }\end{array}$ & 130 & $\mathrm{C}^{\circ}$ \\
\hline \multicolumn{2}{|c}{}
\end{tabular}

\subsubsection{Modeling of gaussian laser distribution}

In the literature, the distribution of the source of heat (laser source) on the surface of the powder bed takes several forms. The gaussian source model is given by the following expression [3]:

$Q_{v}(x, y)=\frac{2 P}{\pi r^{2}} \exp \left(-\frac{2\left(x^{2}+y^{2}\right)}{r^{2}}\right)$ where $\mathrm{P}$ and $\mathrm{r}$ are the parameters of the laser projection process, where their values are proposed and assembled in Table 2.

Table 2 : Mehsless simulation parameters

\begin{tabular}{c|c|c|c}
\hline $\begin{array}{c}\text { Process } \\
\text { parameter }\end{array}$ & Full name & Value & Unit \\
\hline $\mathrm{P}$ & $\begin{array}{c}\text { Mean laser power } \\
(\mathrm{W})\end{array}$ & 1.8 & $\mathrm{w}$ \\
$\mathrm{r}$ & $\begin{array}{c}\text { Laser beam radius } \\
\text { at } 1 / \mathrm{e}^{2}\end{array}$ & 120 & $\mathrm{Um}$ \\
\hline
\end{tabular}

\section{Numerical results and discussion}

With a compture program writting by MATLAB software, using the RBF meshless method, the laser selective sintering of a first layer of nylon 12 powders is simulated in the case of rectangular layer cross section having the following physical dimensions $5 \mathrm{~mm} * 2 \mathrm{~mm} * 1 \mathrm{~mm}$. The temperature at the surface center of powder bed is calculated perpendicular to the projection of the spot laser.

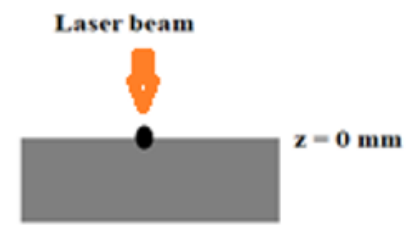

Fig.2 : The position of point at the surface powder bed

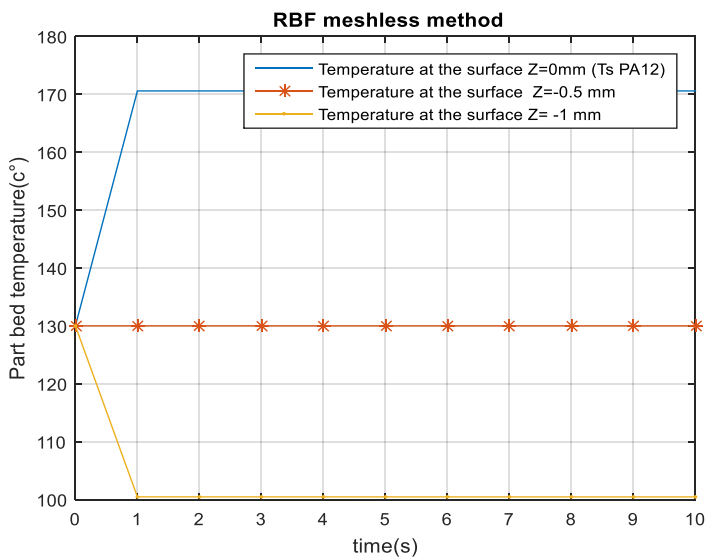

Fig. 3 : Evolution of the temperature at top surface $(\mathrm{z}=0)$, at the middle $(\mathrm{z}=0.5 \mathrm{~mm})$, and bottom powder bed $(\mathrm{z}=-1 \mathrm{~mm})$ ).

It can be noticed from the results obtained in the Fig. 3 that during the projection of the laser beam on the top surface of the powder bed, the temperature is rapidly increasing where the maximum temperature of PA12 is $\left(171.5 \mathrm{C}^{\circ}\right)$, contrary to the case of the laser beam projected at the bottom surface, the temperature decreases rapidly and become constant at $100 \mathrm{c}^{\circ}$, while the temperature remains constant $\left(130 \mathrm{C}^{\circ}\right)$ at the middle of powder bed. 


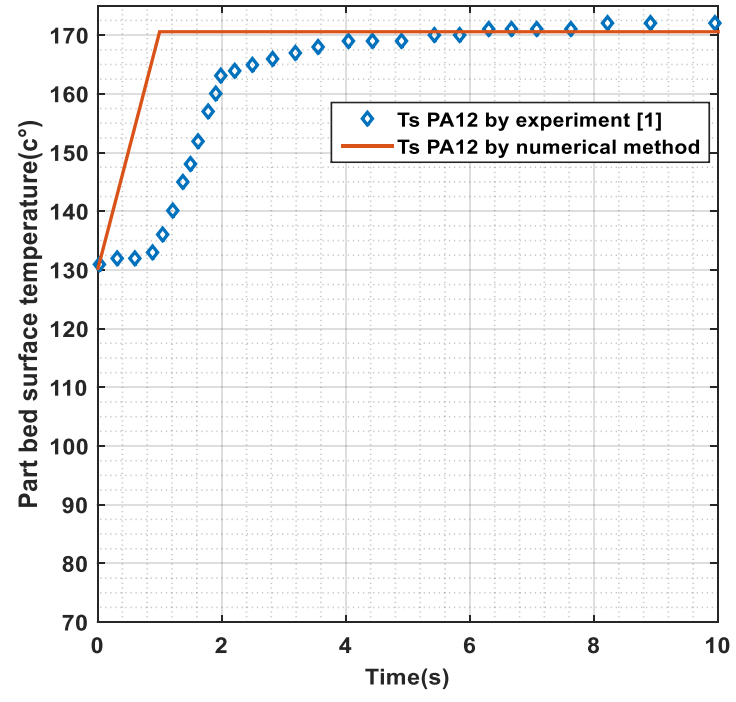

Fig.4 : A comparaison of the result with experimental work (measured Ts evolution on the SLS powder bed surface for PA12 by the chamber infrared sensor[1]).

In the Fig. 4 this model has been validated by comparing the results of the numerical simulation with the results of the experimental work of the author amado[1] (fig.4), which the evolution of the temperature at the surface powder bed Ts was obtained from the measurements taken on the powder bed by the chamber infrared sensor.

\section{Conclusion}

In this study, three dimensional meshfree method is developed for predicting the temperature fields within a first single polyamide layer based on the heat equation with polyamide melting and coupling with radiation and convection phenomena allowing to simulate the thermal history induced by the SLS process.the simulation of the evolution of the temperature at top surface $(\mathrm{z}=0)$, at the middle $(\mathrm{z}=0.5 \mathrm{~mm})$, and bottom powder bed $(\mathrm{z}=-1 \mathrm{~mm}))$ have been done and a comparaison of the result with experimental work allowed to validate a model proposed .

\section{References}

[1] A.Amado \& K. Wegener Schmid, M. / Levy, G.Characterization and modeling of nonisothermal crystallization of Polyamide 12 and coPolypropylene during the SLS process in PMI, International Polymers and Moulds Innovations Conference, 5; 2012,207-216 PMI, International Polymers and Moulds Innovations Conference, 5.

[2] Xiaoyong tian, gang peng. " Process prediction of selective laser sintering based on heat transfer analysis for polyamide composite powders". (2018) state key laboratory of manufacturing systems engineering, 710054, China academy of launch vehicle technology, beijing 100076, china.
[3] Roberts, I. A., C. J. Wang, et al. "A threedimensional finite element analysis of the temperature field during laser melting of metal powders in additive layer manufacturing." (2009), International Journal of Machine Tools and Manufacture, Vol. 49 iss:12 pp. 916-923.

[4] Pepper, D., Sarler, B. Application of Meshless Methods for Thermal Analysis. Journal of Mechanical Engineering, 51(7), (2005).476-483.

[5] R Zamolo1 and E Nobile, Numerical analysis of heat conduction problems on $3 D$ general-shaped domains by means of a RBF Collocation Meshless Method, (2017). IOP Conf. Series: Journal of Physics: Conf. Series 923.

[6] Sara S and Kansa, Multiquadric Radial Basis Function Approximation Methods for the Numerical Solution of Partial differential Equations, (2009) (Advances in Computational Mechanics vol 2) (tech science press).

[7] D.Defauchy, "Simulation du procédé de fabrication directe de pièces thermoplastiques par fusion laser de poudre”, PhD Doctorate Dissertation, Arts et Métiers Paris-Tech, 2013 L. Dong, A. Makradi, S. Ahzi, Y.

[8] Papadatos A. L., "Computer simulation and dynamic control of the selective laser sintering process," M.Sc. thesis, Clemson University, Clemson, U.S.A., (1998).

[9] Papadatos, A., Ahzi, S., Deckard, C. \& Paul, F., "On dimensional stability: modeling the Bonus $Z$ during the SLS process," in Bourell D. L. et al. (Eds.), Proceedings of the Solid Freeform Fabrication (1997), Austin, U.S.A., pp. 709-715.

[10]E. Dumoulin, "Fabrication additive de pièces en polymères thermoplastiques hautes performances et en Polyamide 12 par le procédé de frittage sélectif par laser", PhD Doctorate Dissertation, Mines ParisTech, 2014 S.

[11] Dupin, "Etude fondamentale de la transformation du polyamide 12 par frittage laser: mécanismes physico-chimiques et relations microstructurespropriétés", PhD Doctorate Dissertation, INSA de Lyon, 2012.

[12]Dong, L., Makradi, A., Ahzi, S., \& Rémond, Y., "Finite Element Analysis of Temperature and Density Distributions in Selective Laser Sintering process, " Materials Science Forum - Diffusion in Solids and Liquids II, Vol. 553 (2007), pp. 75-80.

[13] L. Dong, A. Makradi, S. Ahzi, Y. Remond, "Three-dimensional transient finite element analysis of the selective laser sintering process", Journal of Materials Processing Technology, 209(2), (2009), 700-706. 